\section{Unusual nocturnal feeding by Brown Rock- chat Cercomela fusca (Passeriformes: Muscicapidae) in Bikaner, Rajasthan, India}

\section{Partap Singh}

PG Department of Zoology, Govt. Dungar College, Bikaner, Rajasthan 334001, India

Email: partapsk@yahoo.com

Inter-specific and intra-specific competitions have been observed in animals that show behavioural plasticity to optimize their foraging success. Brown Rock-chat Cercomela fusca, which is one of the most common birds around human habitations in Bikaner, Rajasthan, is one such species showing plasticity in its feeding behaviour. The species though diurnal has been observed to engage in nocturnal feeding. Bright sodium lamps attract large number of insects during monsoon period and the Brown Rock-chats voraciously forage upon them. Due to large congregation of insects the capture success in nights is much better as compared to capture rates during the day. Monsoon is the period when their nutritional requirements are very high as they have to nurture young ones. With this behavioural adaptation of nocturnal foraging, Brown Rock-chats have evolved an effective mean to optimize their feeding efficiency.

Because there is a limited amount of organic material that can function as food, a great deal of food competition exists among animals. This competition can be inter-specific or intraspecific. To avoid the competition and to get optimum quantity of food, behavioural evolution has been observed among many birds and mammals. Foraging at night by a diurnal bird is one such example of behavioural adaptation.

Black Drongo Dicrurus macrocercus has been widely observed to engage in nocturnal feeding (Khan 1990; Nameer 1990; Sharma 1991). Even I had observed the species feeding on insects under sodium lamps in Karauli, Rajasthan. Sharma (2003) has observed White-bellied Drongo Dicrurus caerulescens feeding under street lamps during night. Same behaviour has been observed in Tickell's Blue Fly Catcher Cyornis tickelliae (Sharma 2006) and Grey Mongoose Herpestes edwardsii (Sharma 2005).

Brown Rock-chat is one of the most common birds around human habitations in the desert town of Bikaner in Rajasthan. Though Brown Rock-chat is known to be markedly crepuscular

Date of publication 26 April 2009

ISSN 0974-7907 (online) | 0974-7893 (print)

Editor: Rajah Jayapal

Manuscript details:

Ms \# 01852

Received 03 September 2007

Final revised received 08 April 2008

Finally accepted 19 July 2008

Citation: Singh, P. (2009). Unusual nocturnal feeding by Brown Rock-chat Cercomela fusca (Passeriformes: Muscicapidae) in Bikaner, Rajasthan, India. Journal of Threatened Taxa 1(4): 251.

Copyright: (c) Partap Singh 2009. Creative Commons Attribution 3.0 Unported License. JoTT allows unrestricted use of this article in any medium for nonprofit purposes, reproduction and distribution by providing adequate credit to the authors and the source of publication. in its activity pattern, nocturnal foraging has not been documented before. I have observed that the species in Bikaner has unusual behaviour of being active very early in the morning ( 0300 to $0500 \mathrm{hr}$ ) and remain active till very late in the evening (1830 to $2100 \mathrm{hr}$ ). In winters the species remains active till $1830 \mathrm{hr}$ and were foraging till 2000 hr in summers. In particular, Brown Rock-chats were observed feeding under sodium lamps during south-west monsoon in July-August. This strange behaviour of normally diurnal bird

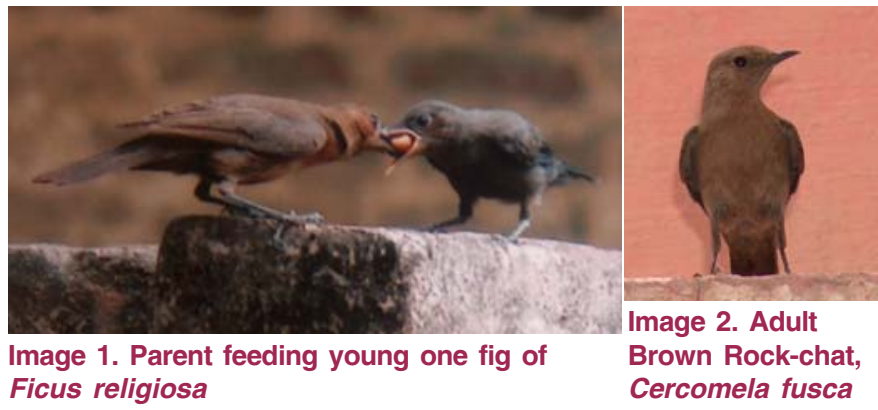

to forage during nights requires some explanation. The studies on reproductive biology indicated that the species has two peaks in reproduction, one in April and the other in July (Singh 2007). During this period their nutritional requirements are very high as they have to nurture young ones. Nocturnal foraging gives species better opportunity to capture insect preys, which congregate under artificial light. In fact, I observed that their capture success is significantly higher during night (13 per hour) than during day (2.5 per hour). By staying close to human habitations they also avoid natural predators of night. The dark brown body color gives them added advantage of becoming invisible in the darkness. It is therefore speculated that Brown Rock-chats in the city of Bikaner have developed nocturnal foraging as a behavioural adaptation which tend to increase its feeding efficiency and optimize food acquisition with less competition.

\section{References}

Khan, A.R. (1990). Feeding habits of Black Drongo. Newsletter for Birdwatchers 30(10\&11): 11 .

Nameer, P.O. (1990). Midnight feeding by Black Drongo. Nerwsletter for Birdwatchers 30(7\&8): 9.

Sharma, S.K. (1991). Nocturnal feeding by Black Drongo. Newsletter for Birdwatchers 31(3\&4): 8 .

Sharma, S.K. (2003). Nocturnal feeding by White-bellied Drongo Dicrurus caerulescens. Journal of Bombay Natural History Society 100(1): 144.

Sharma, S.K. (2005). Unusual nocturnal activity of a Grey mongoose Herpestes edwardsii in Bandipur Tiger Reserve, Karnataka. Zoos' Print $20(7): 21$.

Sharma, S.K. (2006). Nocturnal feeding by the Tickell's Blue Flycatcher Cyornis tickelliae. Zoos' Print Journal 21 (2): 2171.

Singh, P. (2007). Ecological and ethological studies on Brown Rockchat Cercomela fusca in Bikaner region of Thar desert. Final Project Report submitted to UGC. 